\title{
HEALTH SURVEY AMONG PEOPLE LIVING NEAR AN ABANDONED MINE. A CASE STUDY: JALES MINE, PORTUGAL
}

\author{
OLGA N. MAYAN ${ }^{1, *}$, MARIA J. GOMES ${ }^{2}$, AMÉLIA HENRIQUES ${ }^{1}$, SUSANA SILVA ${ }^{1}$ \\ and ANDREA BEGONHA ${ }^{1}$ \\ ${ }^{1}$ Center of Environmental and Occupational Health, National Institute of Health Porto - Portugal; \\ ${ }^{2}$ School of Health, Politechnic Institute of Bragança-Portugal \\ (*author for correspondence,e-mail: olgamayan@insa.min-saude.pt)
}

(Received 21 July 2005; accepted 7 October 2005)

\begin{abstract}
Campo de Jales is a village surrounding the abandoned Jales mine. The area is heavily contaminated with heavy metals and dusts from large tailings piles as result of centuries of mining operations. The aim of this study is to investigate potential health threats associated with site contamination. The population studied comprised two groups: people living in Campo de Jales $(n=229)$ and a control group - people living in Vilar de Macada $(n=234)$. Lead and cadmium exposure and symptoms survey were carried out.

The results showed a significant higher levels of blood lead and cadmium between the Campo de Jales residents (lead: $9.5 \mathrm{microgr} / \mathrm{dl}$ versus $7.7 \mathrm{microgr} / \mathrm{dl}$; cadmium: $0.84 \mathrm{microgr} / \mathrm{dl}$ versus 0,65 microgr/dl) as well as to a higher prevalence of respiratory and irritation symptoms and great concern about his own health.

In conclusion: community is the scene of long-term health problems resulting from the site environmental contamination.
\end{abstract}

Keywords: biological monitoring, cadmium exposure, contaminated sites, lead exposure, mines

\section{Introduction}

Portugal has a long history of mining activities, dating back to prehistoric times. The Jales mining belt site is an inactive gold mining area located in the Vila Real district, in the Northeast of Portugal. The site encompasses the abandoned industrial complex and a village (Campo de Jales) with a population of approximately 900 people.

Mining began at Jales during the Roman Empire, and declined when the Romans left the Iberian Peninsula. In the early nineties, large-scale mining had taken place, with underground mining of the veins, using adits and shafts, which replaced the initial open cut mining. Industrial exploration of the Jales' mines was abandoned in 1992.

Mining activities had carried out an important role for local and national economy; however they were performed in an uncontrolled way, and gave rise to great soil erosion and a serious environmental contamination.

Exploration of the mines left several unsafe and unhealthy conditions, such as abandoned structures and equipment, highwalls, open pits and mining dumps tailings, lack of drainage control, acid water and toxic materials. Large quantities 
of waste, about 5 million tones of fine grained material, were deposited and piled up on the site; this piles are uncovered and unstable (Lancastre, 1996).

The mines' exploitation and close up conditions has caused great erosion soil and has been detrimental to the environment, by contaminating water (surface waterthe river Tua - and ground water) soil and wetland sediments, and biota. The site also suffers from air pollution, as large amounts of particles from the waste piles are cast by the wind.

A site contamination assessment was developed and the contaminants of concern were identified. Samples of ground and surface water, soil and wetland sediments were collected and analyzed (Oliveira et al., 1995).

The results point out the contamination of water, soil and sediments. The main pollutants were heavy metals, with elevated concentrations of manganese, cadmium, lead and arsenic being found (Oliveira et al., 1995).

In face of these results, a public water supply system was installed, and the community was advised not to use private wells.

However, there remain other potential exposure pathways for the residents, namely the inhalation of particles, contact with dust and the potential consumption of contaminated food (local vegetables and animals).

The lack of reliable information on the health impact related to the contamination of the site draw attention to the need of a community health study. The present study, a case-control study, aims to investigate health effects and concerns, and cadmium and lead exposure associated with environmental contamination in Campo de Jales.

\section{Material and Methods}

\subsection{STUdy SUbJeCTS}

The health effects and cadmium and lead exposure were studied among Campo de Jales inhabitants. A control group was formed by people living in Vilar de Maçada, located about $45 \mathrm{~km}$ Northeast of Campo de Jales. This village is not in the vicinity of a mine complex or other industrial units, and is similar to Campo de Jales, with the same geological, economical and demographic characteristics, as well as lifestyle.

The inclusion criteria for the study population were: that the subjects had never worked in mines, or other activities with potential exposure to heavy metals; and that their age was greater than 15 years old.

The population of the two groups (cases and control) was stratified by sex and age.

A random sample of 250 inhabitants of Campo de Jales was selected. This selection kept the same percentage of each subgroup (sex and age) found on the total population.

In the control group we randomly selected, in each subgroup, the same number of individuals than in the case group. 
TABLE I

Distribution of individuals

\begin{tabular}{lcc}
\hline Subjects & Campo de Jales & Vilar de Maçada \\
\hline Selected study population & 250 & 250 \\
Absence & 7 & 8 \\
Refusals & 3 & 5 \\
Disease (respiratory) & 11 & 3 \\
Final study population & 229 & 234 \\
\hline
\end{tabular}

Fifteen individuals ( 7 cases and 8 controls) were not interviewed due to absence from their home during the survey. Eight individuals ( 3 cases and 5 controls) refused to participate, when asked to give informed consent prior to the start of the interview. Altogether 229 inhabitants of Campo de Jales and 234 inhabitants of Vilar de Maçada (response rate of $95.4 \%$ ) were interviewed.

Fourteen subjects (11 cases and 3 controls) were excluded, because they suffered from respiratory diseases (asthma and bronchitis). Therefore the final study population consisted of 229 cases and 234 controls. (see Table I).

\subsection{Health impact assessment}

The study was developed in accordance with the Helsinki declaration (guidelines in biomedical research involving human subjects) (World Medical Association, 1994). Several meetings with authorities, health professionals and the community were taken, in order to inform about the study's aims and methodology, and a written informed consent was given prior to the start of the study.

The health impact evaluation included the study of symptoms experienced by the people, their health concerns, and the evaluation of cadmium and lead exposure levels.

\subsubsection{Health Effects and Concerns Assessment}

To characterize the health status and concerns we analyzed the information on prevalence of symptoms, prevalence of diseases and health concerns.

The information was collected by a door-to-door interview, using a questionnaire. The interview was conducted by public health nurses.

The questionnaire elicited information about: demographic characteristics, education, life style, namely tobacco and alcohol consumption, and professional history; diseases of the individual and of family members were also inquired. There was a group of questions about symptoms that could be related to the toxicological profiles of the main contaminants of Campo de Jales site: dust and heavy metals (cadmium and lead). The symptoms evaluated were respiratory, digestive, sensorial (including lost of smell), neurological and mucous and eye irritation. It was also 
included one question about health concerns (evaluated by the periodicity of visits to the family physician for medical surveillance).

The level of complaints for the studied symptoms was expressed by the study participants using a scale of: $0=$ never; $1=$ sometimes; $2=$ often; $3=$ very often.

Classification of smoking habits was made on the basis of: non-smoking (score 1 ); 1-4 cigarettes per day (score 2 ); $>5$ cigarettes per day (score 3 ).

\subsubsection{Cadmium and Lead Exposure}

Exposure to cadmium and lead was evaluated by biological monitoring, using as biomarkers cadmium and lead levels in the blood.

Blood samples were collected by venipuncture using lead-free sterile containers (with EDTA as anticoagulant) and were stored at $4{ }^{\circ} \mathrm{C}$.

The determination of cadmium and lead in blood was carried out with a wellestablished method based on graphite furnace atomic absorption spectrofotometry (GFAAS) (Miller et al., 1983; Subramanian et al., 1981).

The method employs a whole blood sample dilute in a mixed matrix modifier containing Triton X-100, nitric acid and dibasic ammonium phosphate. An aliquot of dilute sample is automatically delivered to a pyrolytic/graphite platform furnace cuvette by the discrete autosampler. The spectrometer is calibrated by aqueous standards automatically prepared by the autosampler through dilutions of concentrated stock solutions and deionized water, The concentrated mixed matrix modifier solution used in the Auto-Cal routine is prepared at $10 \times$ the concentration used to dilute the blood samples. The stock $\mathrm{Cd}$ and $\mathrm{Pb}$ standards are at $100 \mathrm{ppb}$. The quick furnace method program completes the analysis of a blood sample in approximately $130 \mathrm{~s}$.

The method has been validated against international blood $\mathrm{Cd}$ and $\mathrm{Pb}$ reference materials from the EU Community Bureau of Reference - Belgium (EU BCR ${ }^{\circ}$ 194). The laboratory also participate successfully in two international interlaboratory programs for $\mathrm{BCd}$ and $\mathrm{BPb}$ (ICP - Interlaboratory Comparison Program Institut National de Santé Publique, Québec and PICC-Pb (Program Interlaboratorios de Control de Calidad - Zaragoza, Spain).

For the purposes of this study, all blood specimens were analyzed in duplicate (triplicate wherever possible).

The detection limits were found to be: $\mathrm{Cd}=0.10$ microgr $/ \mathrm{l} ; \mathrm{Pb}=1.0 \mathrm{microgr} / \mathrm{dl}$.

The precision established for the analytical system at various blood- cadmium and blod-lead levels was the relative standard deviation (RSD) were: $\mathrm{Cd}=3.8 \%$ (1-5 microgr/l) and $\mathrm{Pb}=3.2 \%$. (5-25 microgr/dl).

Accuracy was assessed by analyze a standard reference material BCR (CRM 194). The mean measured concentrations were:

$-\mathrm{Cd}=0.52$ microgr $/ \mathrm{l}(\mathrm{SD}=0.18, n=5$, results obtained on the same day with different aliquots) with $95 \%$ confidence limits of \pm 0.08 microgr $/ 1$, against a certificate value of $0.5 \pm 0.1$ microgr/l ( $95 \%$ confidence limit) 
$-\mathrm{Pb}=12,9$ microgr/dl $(\mathrm{SD}=4.9, n=5$, results obtained on the same day with different aliquots) with $95 \%$ confidence limits of $\pm 1.3 \mathrm{microgr} / \mathrm{dl}$, against a certificate value of $12.6 \pm 0.4 \mathrm{microgr} / \mathrm{dl}$ ( $95 \%$ confidence limit).

\subsection{STATISTICAL ANALYSIS}

Homogeneity between groups for some variables (professional activity, academic degree and tobacco and alcohol consumption) was checked by the Chi-square test. Descriptive statistics (mean, SD, median and range) were used to describe the blood cadmium and lead levels. The statistical analysis of differences in blood cadmium and lead levels in the two groups (cases and controls) was carried out using the t-test. All of the collected information was analyzed by logistic regression. Odds ratio (95\% confidence interval) was calculated to evaluate health concern. All the analyses were performed with an SPSS statistical package (version 10.5) (SPSS Inc., Chicago, IL). The level of significance was set at $p<0.05$.

\section{Results}

The demographic characteristics as well as other characteristics of the study and control populations were shown in Table II and Figure 1.

Demographic data showed that women and young and old individuals were prevalent. This could be explained because there are no industrial activities in Campo de Jales, so some young people must migrate to other places.

We checked the homogeneity between the two groups and no significant differences were found in tobacco consumption, eating habits and leisure activities. Significant difference was found in alcohol consumption, with more heavy drinkers

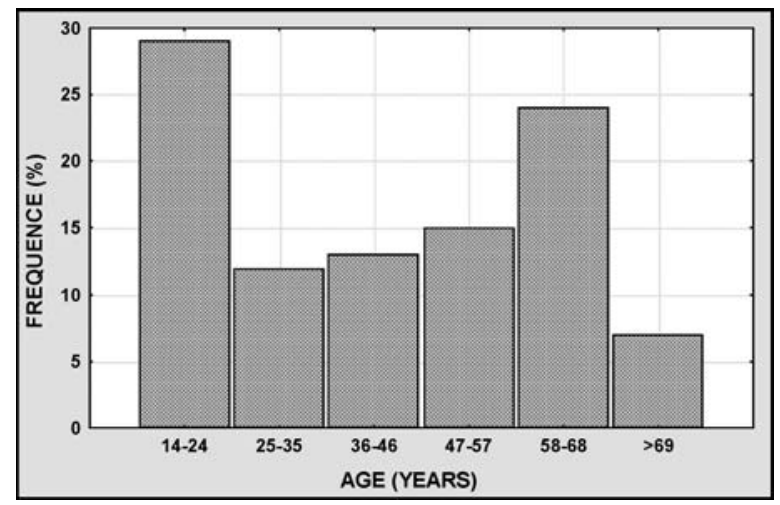

Figure 1. Study population: age distribution. 
TABLE II

Population characteristics

\begin{tabular}{|c|c|c|}
\hline & $\begin{array}{l}\text { Campo de Jales } \\
\text { study population }\end{array}$ & $\begin{array}{l}\text { Vilar de Maçada } \\
\text { control population }\end{array}$ \\
\hline \multicolumn{3}{|l|}{ Gender } \\
\hline Female $(n)$ & 139 & 142 \\
\hline Male $(n)$ & 90 & 92 \\
\hline Age (mean \pm SD; min-max $)$ & $42.1 \pm 18.7 ; 15-86$ & $41.9 \pm 19.7 ; 15-90$ \\
\hline \multicolumn{3}{|l|}{ Marital status } \\
\hline Single, divorced, widow & 94 & 88 \\
\hline married or living as married & 135 & 146 \\
\hline \multicolumn{3}{|l|}{ Education grade } \\
\hline Primary level & 100 & 103 \\
\hline Secondary level & 120 & 119 \\
\hline University level & 9 & 12 \\
\hline \multicolumn{3}{|l|}{ Working activity } \\
\hline Agriculture/forestry & 119 & 123 \\
\hline Industry & 45 & 40 \\
\hline Services & 24 & 19 \\
\hline Retired/students & 41 & 52 \\
\hline \multicolumn{3}{|l|}{ Life style } \\
\hline Alcohol consumption (no; yes) & $110 ; 119$ & $145 ; 89$ \\
\hline Smoking habits (no; yes) & $151 ; 78$ & $149 ; 85$ \\
\hline
\end{tabular}

TABLE III

Symptoms prevalence

\begin{tabular}{|c|c|c|c|c|}
\hline \multirow[b]{2}{*}{ Symptoms } & \multicolumn{2}{|c|}{ Prevalence $(\%)$} & \multirow{2}{*}{$\begin{array}{l}\text { Odds ratio } \\
\text { Cases compared } \\
\text { to controls }\end{array}$} & \multirow{2}{*}{$\begin{array}{l}95 \% \\
\text { confidence } \\
\text { intervals }\end{array}$} \\
\hline & Cases & Controls & & \\
\hline Shortness of breath & 16.5 & 14.8 & 2.002 & $1.71-4.99$ \\
\hline Cough & 17.4 & 13.8 & 2.133 & $1.24-3.19$ \\
\hline Sneeze & 21.3 & 14.0 & 3.542 & $2.32-5.41$ \\
\hline Hoarse, dry throat & 11.9 & 9.2 & 2.010 & $1.43-3.09$ \\
\hline Itching, irritation of eyes & 24.1 & 11.9 & 5.533 & $3.59-8.70$ \\
\hline Anosmia (lost of smell) & 5.1 & 2.8 & 2.561 & $1.11-5.45$ \\
\hline
\end{tabular}

in the control group. This difference, lead us to adjustments when comparing health outcomes between the two groups.

Table III list the symptoms for which we found significant differences in prevalence data between the two groups. 
TABLE IV

Medical surveillance

\begin{tabular}{lll}
\hline & \multicolumn{2}{c}{$\begin{array}{c}\text { Medical surveillance (\%) } \\
\text { (at least once a year) }\end{array}$} \\
\cline { 2 - 3 } Group & Yes & No \\
\hline Campo de Jales & 62.5 & 37.5 \\
Vilar de Maçada & 41.2 & 58.8 \\
\hline
\end{tabular}

TABLE V

Blood cadmium levels (microgr/l)

\begin{tabular}{llllll}
\hline & Mean & SD & $\begin{array}{l}\text { 95\% Confidence } \\
\text { limits for mean }\end{array}$ & Median & Min-Max \\
\hline Campo de Jales & 0.84 & 0.58 & $0.72-0.96$ & 0.79 & $0.15-2.01$ \\
Vilar de Maçada & 0.65 & 0.30 & $0.59-0.71$ & 0.63 & $0.14-1.85$ \\
\hline
\end{tabular}

TABLE VI

Blood lead levels (microgr/dl)

\begin{tabular}{llllll}
\hline & Mean & SD & $\begin{array}{l}\text { 95\% Confidence } \\
\text { limits for mean }\end{array}$ & Median & Min-Max \\
\hline Campo de Jales & 9.52 & 3.90 & $8.74-10.30$ & 8.80 & $3.4-23.6$ \\
Vilar de Maçada & 7.73 & 2.87 & $7.16-8.31$ & 7.65 & $1.8-17.5$ \\
\hline
\end{tabular}

The results showed that the odds ratio for having more respiratory symptoms and anosmia doubled for the inhabitants of Campo de Jales. Also, the odds ratio of suffering of eye irritation was more than five times greater for those living in Campo de Jales.

Concern about the health effects of environmental contamination was greater in the inhabitants of Campo de Jales. More individuals in the "cases" regularly visited the family physician for medical surveillance than in the control group, as presented in Table IV.

Campo de Jales' inhabitants reported more cases of respiratory disease (11 vs. 3 ) and cancer disease in family members (5 vs. 3) than those of Vilar de Maçada.

Tables V and VI show the results of cadmium and lead concentrations in the blood, separated by groups.

The results of blood cadmium and lead concentrations portrayed a significantly higher exposure $(p=0.000)$ for people living in Campo de Jales (Figures 2 and 3). 


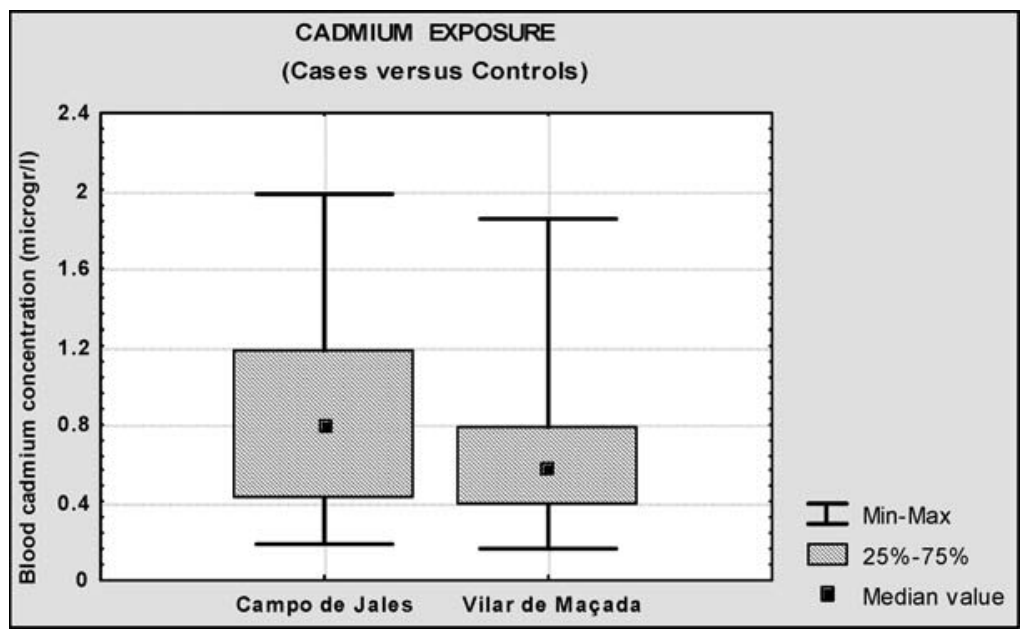

Figure 2. Blood cadmium concentrations.

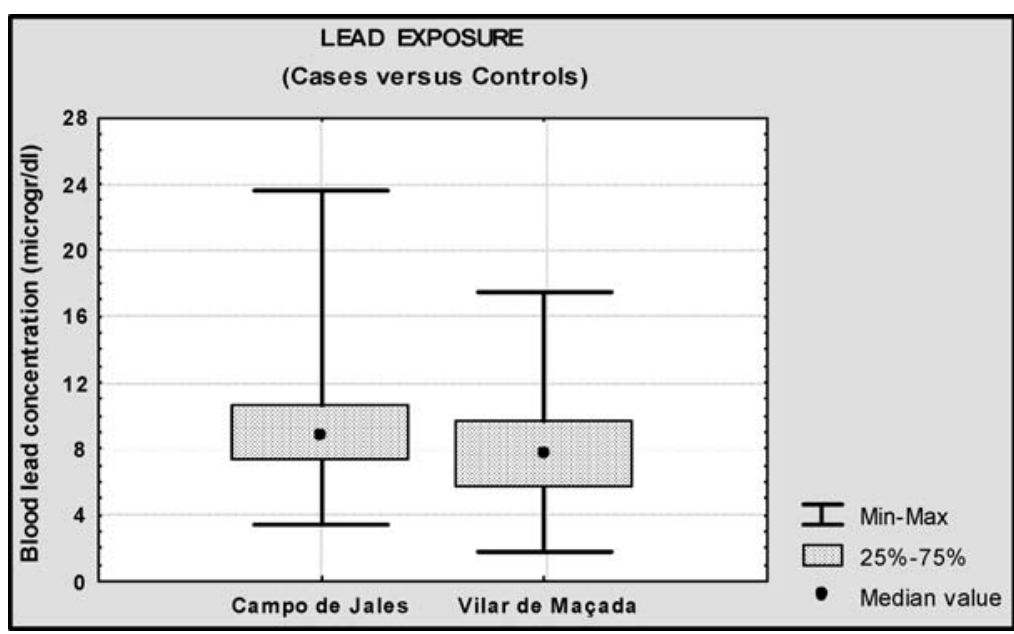

Figure 3. Blood lead concentrations.

\section{Discussion and Conclusion}

The results of this study showed that the contamination on the site had an impact on the health of the community.

The inhabitants of Campo de Jales evidenced an higher exposure to cadmium and lead. However, results showed that exposure levels were lower than they had been predicted, as based on the site contamination assessment that took place in 1997. This could be explained by the preventive measures that were since taken installation of a public water supply system, and water quality surveillance. 
In comparison with the control group, complaints are reported to a significantly higher degree by subjects located in the vicinity of abandoned Jales mines, with a higher prevalence of eye irritation and mucous and respiratory symptoms being denounced. These symptoms could be originated by dust emanating from the waste piles. On the other hand, sensorial symptoms (lost of smell), for which a higher prevalence was also found, was correlated with blood cadmium levels.

The results also points out for more respiratory diseases and cancer disease within Campo de Jales.

The community showed great concern about the effects of environmental contamination.

Our results are in accordance with other studies developed on the health impact of living on contaminated sites. Mining sites usually envelope soil contamination and an higher exposure to heavy metals for the population residing in the area (Asonso et al., 2001; Paoliello et al., 2002).

Finally, the results of this study reinforced the need for the implementation of a comprehensive plan for the cleaning up the mining complex site. This plan must be developed with the active involvement of the community.

A restoration programme is now ongoing, until 2010, which includes the following actions: stabilization of old mines buildings for historical interpretation; procedures for closing mine addits and shafts; procedures for containing mine wastes and bioremediation. Some measures have been taken in order to diminish soil erosion and dispersion of contaminants to the surroundings (Bleeker et al., 2003).

\section{Acknowledgements}

This study was supported by Comissão de Fomento da Investigação em Cuidados de Saúde - Ministério da Saúde. The authors are grateful to public health authorities and community of Campo de Jales and Vilar de Maçada.

\section{References}

Alonso, E., Cambra, K. and Martinez, T.: 2001, 'Lead and cadmium exposure from contaminated soil among residents of a farm area near an industrial site', Arch Environ Health 56(3), 278282.

Bleeker, P.M., Teiga, P.M., Santos, M.H., de Koe, T. and Verkleij, J.A.: 2003, 'Ameliorating effects of industrial sugar residue on the Jales gold mine spoil (NE Portugal) using Holcus lanatus and Phaseolus vulgaris as indicators', Environ Pollut. 125(2), 237-244.

Lancastre, S.M.: 1996, 'As minas de Jales', Bol Minas, Lisboa 3, 177-190.

Oliveira, J.M., Santos e. Ávila and Freire, P.: 1995, 'Avaliação do impacto químico ambiental provocado por uma exploração mineira. Um caso de estudo na mina de Jales', Estudos, Notas e Trabalhos. IGM. 25-50 
Paoliello, M.M., De Cpitani, E.M., Cunha, F.G., Matsuno, T. and Carvalho, M.F.: 2002, 'Exposure of children to lead and cadmium from a mining area of Brasil', Environ Res. 88(2), 120-128.

Miller, D.T., Paschal, D.C., Gunter, E.W., Stroud, P.E. and D’Angelo, J., 1987, 'Determination of lead in blood using electrothermal atomization atomic-absorption spectrometry with a L'ovv platform and matrix modifier', Analyst 112, 1701-1704.

Subramanian, K.S. and Meranger, J.C.: 1981, 'A rapid electrothermal atomic absorption spectrophotometric method for cadmium and lead in human whole blood', Clin. Chem. 27, 1866-1871.

World Medical Association: 2004. 'Declaration of Helsinki: Ethical principles for medical research involving human subjects', J. Int. Bioethique. 15(1), 124-129. 